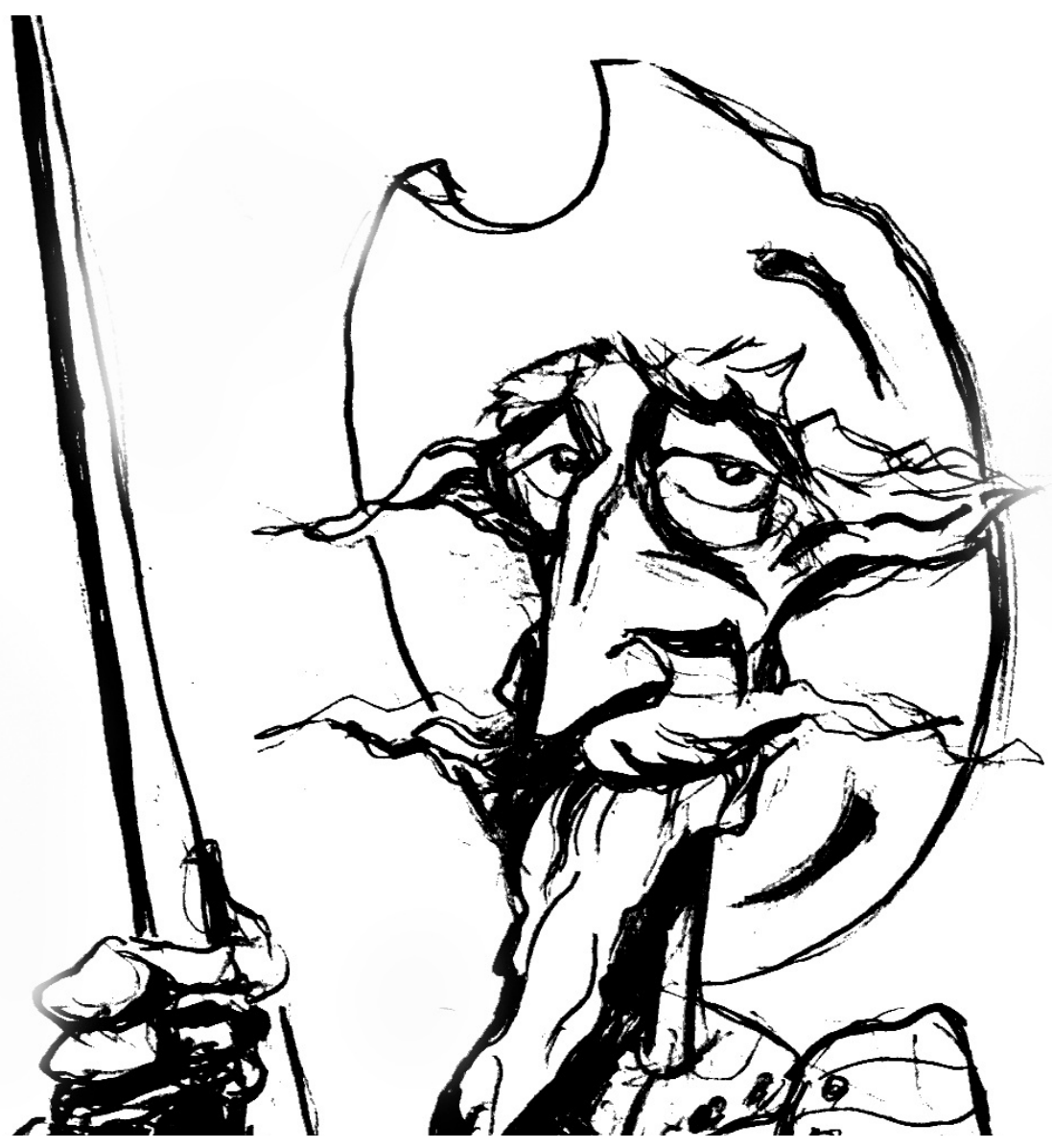

La primera elección presidencial de Luis Alberto de Herrera desde el discurso del candidato y la prensa partidaria (1922)

[Carolina Cerrano, José Antonio Saravia] 



\title{
La primera elección presidencial de Luis Alberto de Herrera desde el discurso del candidato y la prensa partidaria (1922)*
}

\author{
The First Presidential Election of Luis Alberto de Herrera from the \\ Candidate's Speech and the Partisan Press (1922) \\ CAROLINA CERRANO \\ JOSÉ ANTONIO SARAVIA
}

\section{Resumen}

Este artículo estudia la primera elección presidencial de Luis Alberto de Herrera como candidato del Partido Nacional uruguayo en 1922. En aquel tiempo su liderazgo carismático y su arrastre popular estaban en sus inicios, a diferencia del culto característico de los siguientes años. Este trabajo muestra cómo Herrera y el Partido Nacional -a partir del análisis de sus discursos políticos y de la prensa nacionalistahicieron su propaganda electoral, y si bien el resultado fue adverso cosecharon gran número de votos acortando las distancias que lo separaban de su tradicional adversario colorado.

\section{Palabras claves}

Luis Alberto de Herrera; Partido Nacional (Uruguay); Campaña Presidencial 1922; Prensa Nacionalista; Discursos Políticos.

\begin{abstract}
This article studies the first presidential election of Luis Alberto de Herrera as candidate of the Uruguayan National Party in 1922. At that time his charismatic leadership and popular attraction were in their early days, unlike the characteristic cult of the following years. This work -based on the analysis of their political speeches and the nationalist pressshows how Herrera and the National Party made their electoral propaganda, and although the result was adverse, they garnered a large number of votes, shortening the distances that separated them from their traditional Colorado adversary.
\end{abstract}

Key words

Luis Alberto de Herrera; National Party (Uruguay); Presidential Campaign 1922; Nationalist Press; Political Speeches.

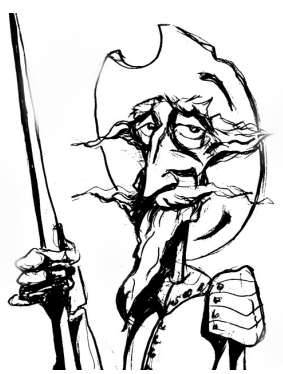

Recibido con pedido de publicación el 18 de agosto de 2020

Aceptado para su publicación el 13 de noviembre de 2020

Versión definitiva recibida el 12 de enero de 2021

Carolina Cerrano, Universidad de Montevideo - Agencia Nacional de Investigación e Innovación, Montevideo, Uruguay; e-mail: ccerrano@um.edu.uy

José Antonio Saravia, Universidad Rusa de la Amistad de los Pueblos, Moscú, Rusia; e-mail: joseasaravia@outlook.com

* Agradecemos la lectura y valiosos aportes que han hecho a este artículo el Dr. Luis Fernández Torres y el Dr. Daniel Corbo, como así también a los evaluadores anónimos de la revista.

Esta obra se publica bajo licencia Creative Commons. Atribución-NoComercial-CompartirIgual 4.0 Internacional

Cerrano, Carolina y Saravia, José Antonio “La primera elección presidencial de Luis Alberto de Herrera desde el discurso del candidato y la prensa partidaria (1922)", Prohistoria, Año XXIV, núm. 35, jun. 2021, pp. 55 - 78 


\section{Introducción}

En este artículo se aborda la primera campaña presidencial del historiador y político del Partido Nacional uruguayo Luis Alberto de Herrera en noviembre de 1922. Esas elecciones cosecharon su primera derrota electoral, a la que más tarde se sumarían las de 1926, 1930, 1946, 1950 y 1958. Herrera (1873-1959), hijo de un político nacionalista, desde muy joven inició su actividad política en el Club Paysandú (1893) y en el periodismo. Participó en las revoluciones blancas de 1897 y de 1904 por la búsqueda de garantías electorales, frente al fraude organizado como práctica de los gobiernos colorados, lo que imposibilitaba la rotación de los partidos en el poder. En 1904, Herrera se desempeñaba como diplomático en la legación uruguaya en Washington y regresó para combatir junto al caudillo Aparicio Saravia, quien fue abatido en la última guerra civil del país, convirtiéndose en una de las figuras emblemáticas del Partido Nacional y cuya memoria se mantiene vigente en el siglo XXI. En relación con ello, Herrera le profesaba a nivel personal y público un culto especial a Saravia, debido a los valores que este encarnaba en su lucha contra el Partido Colorado, así como al fundador de su partido Manuel Oribe.

Desde la muerte de Saravia, Herrera fue un firme partidario de abandonar la vía armada y potenciar la acción pacífica del partido para que Uruguay alcanzara una democracia política plena. En 1905 ingresó a la Cámara de Diputados. El 30 de julio de 1916 se celebraron las primeras elecciones con sufragio universal masculino y secreto para una convención de reforma constitucional. Este acontecimiento fue muy significativo en la historia partidaria como una demostración de que era posible vencer a su principal adversario con elecciones libres y con garantías, por lo que sería evocado en futuros comicios. Herrera participó en la convención constituyente y apoyó, entre otras reformas, la separación de la Iglesia y el Estado. La constitución de 1917 estableció un poder ejecutivo bicéfalo, compuesto por el presidente responsable de las carteras de interior, defensa y relaciones exteriores y un Consejo Nacional de Administración (CNA), de nueve miembros, seis del partido más votado y tres de la minoría, que tenía a su cargo Hacienda, Industrias, trabajo y comunicaciones, Justicia e instrucción pública, y Obras públicas (Oddone, 1955: 118). Este organismo funcionaría hasta el golpe de Estado de 1933. El CNA concretaba la coparticipación en el poder ejecutivo nacional y en cargos jerárquicos de la administración pública. Esta fue una de las singularidades del proceso de construcción democrática uruguaya que recogía legados de fines del siglo XIX, además, es importante considerar que 
esta tradición de coparticipación se mantendría en diferentes grados y etapas durante el siglo $\mathrm{XX}, \mathrm{y}$, de hecho, algunos vestigios llegan al presente. ${ }^{1}$

Herrera se tituló en doctor en Derecho, pero no ejerció la profesión. En las primeras décadas del siglo compaginó su actividad política con la del oficio del historiador, y sus diferentes obras tuvieron gran repercusión regional. ${ }^{2}$ En los últimos treinta años de su vida menguó su producción histórica, aunque no así la actividad partidaria-periodística. Para el intelectual uruguayo Carlos Real de Azúa (1994), Herrera fue de los "pocos políticos divertidos" del país: "humor y antisolemnidad integran, con otros elementos, el compuesto de la poderosa capacidad atractiva y movilizadora" (21). Eduardo Víctor Haedo (1990), uno de discípulos, en su biografía señala su capacidad de "transformar anécdotas en parábolas", su "memoria prodigiosa", y le adjudicó, sin dudarlo, el título de "prócer de América" (34). El historiador Carlos Zubillaga (1976) sostiene que "su acción política de más de medio siglo configura una de las claves del Uruguay contemporáneo" (8). Entre sus virtudes le reconoce el pragmatismo, cuya biografía política confirma, y el rechazo al purismo académico (19-20). Al igual que sus otros biógrafos, remarca su "lenguaje llano, picante, pleno de modismos camperos y de valores entendidos” (21).

Herrera fue admirado por sus acólitos, a quienes movilizó en cientos de miles, aunque a la par despertó la inquina de muchos correligionarios nacionalistas. Sin embargo, en la campaña presidencial de 1922 su liderazgo y preponderancia estaban en sus inicios, por lo que todavía no se observan el culto y fervor que le profesarían las masas, sus discípulos y propagandistas en las siguientes décadas de su vida. En aquel momento, el Partido Nacional estaba dividido en dos fracciones mayoritarias: la herrerista y principista, que compartían homogeneidad ideológica en cuanto a la tradición y objetivos republicanos del partido, estaban unidas por un furibundo antibatllismo y un anhelo de llegar al poder. Los principistas discrepaban con el estilo de conducción de Herrera, lo que fue dejado de lado en el afán de unir al partido y obtener el triunfo electoral que ansiaban concretar, motivados por un caudal electoral creciente desde 1916 y a la par se combinaba con un retroceso de sufragios del batllismo (Caetano, 1983: 81-82). ${ }^{3}$ A fines de 1920, Herrera,

${ }^{1}$ El bipartidismo es un rasgo característico de la cultura política uruguaya hasta fines del siglo XX. Para ampliar sobre este tema y la coparticipación véase: Corbo (2019), Caetano (2014) y Rilla (2008: 113-130; 274-275).

${ }^{2}$ La biografía intelectual de Herrera más completa para las tres primeras décadas del siglo XX es la de Laura Reali (2016), en especial, se recomienda el apartado que dedica al libro de Herrera: La Revolución francesa y Suramérica donde reconstruye aspectos medulares de su cosmovisión histórica-política (73-133).

${ }^{3}$ Sobre la historia del Partido Nacional en las primeras décadas del siglo XX se recomiendan dos libros que nacieron de tesis doctorales: Corbo (2019) y Reali (2016). Romeo Pérez Antón (2018) aclara que en 1922 el término herrerista o herrerismo no formaba parte del lenguaje político de la época. Asimismo recuerda que si bien el liderazgo de Herrera estaba en sus inicios, es 
presidente del directorio del Partido Nacional, aceptó un pedido de Lorenzo Carnelli, líder de los radicales blancos, de ser una fracción diferenciada y con personería jurídica propia dentro del Partido Nacional (Zubillaga, 1979: 34). Este grupo minoritario "defensor de un programa ideológico renovador" no fue percibido en ese momento con alarma o preocupación, situación muy disímil a la de las elecciones presidenciales de 1926 y 1930 (Zubillaga, 1979, Vanger 2012, Cerrano y Saravia, 2020).

Finalmente, el colorado José Serrato alcanzó la primera magistratura, con 94.462 sufragios, a pesar de haber obtenido individualmente menos votos que Herrera (117.901) (Caetano: 1993, 64). Según la ley de lemas, en vigencia desde 1910, los partidos podían registrar varios sublemas, representativos de sus distintas tendencias, en una elección. Esto les permitía sumar sus votos en un lema común (Lindahl, 1971: 133, 66-67). El nacionalismo presentó a Herrera como candidato único, tema que se desarrolla en este trabajo. En aquella época, los colorados estaban divididos en varias fracciones, y eran conscientes de que, si alguna de ellas se independizaba y no acordaba formar parte del lema Partido Colorado, los nacionalistas podrían alcanzar el poder. En la suma final los colorados obtuvieron 5.175 votos más que Herrera. ${ }^{4}$

José Batlle y Ordóñez, presidente del país entre 1903-1907 y 1911-1915, era el líder del sector batllista, quien desempeñaba roles ambivalentes, por un lado, era el artífice de las fragmentaciones del Partido Colorado y al mismo tiempo su figura preponderante era la que comandaba la estrategia de unidad partidaria en las elecciones. Serrato fue el candidato batllista, pero era un personaje neutral o independiente que no generaba rechazo categórico por parte de las otras tendencias (Caetano, 1993: 78). Batlle y Ordóñez dejó un sello duradero en la cultura política uruguaya, en cuanto a la profundización del laicismo y el anticlericalismo, a la par del proceso de reformas sociales, culturales y económicas avanzadas, lo que le permitió mantener a fieles acólitos. No obstante, sus correligionarios se dividieron y limitaron su programa reformista una vez finalizada su segunda presidencia. ${ }^{5}$

Este artículo busca ser un aporte en profundidad al estudio de la primera contienda presidencial de Herrera desde la prensa nacionalista. Igualmente, contribuir a una historiografía que en general está más centrada en el gobierno que en la oposición. Las fuentes de la investigación son el diario La Democracia,

importante considerar que no "se trataba, notoriamente, de un principiante o de un improvisado" (110). Con los reparos propuestos y a fines prácticos en este trabajo se usa el término herrerismo cuando se refiere a los simpatizantes del candidato presidencial por parte de La Democracia.

4 Otros trabajos que abordan la campaña electoral de 1922, contemplando también a los colorados son los de: Caetano (1993: 124-133), Lindalh (1971: 112-119, 124-133), Manini Ríos (1972: 172-245). También Haedo (1990b), partidario y amigo, de Herrera (27-42).

${ }^{5}$ Sobre el batllismo, véase: Caetano (2011); Barrán y Nahum (1981). 
fundado en julio de 1921, al "servicio de Herrera", quien "lo utilizó para señalar el rumbo a su Partido y hacer realidad su candidatura presidencial" (Reyes Abadie, 1989: 176) y El País, un medio que sobrevive en la actualidad, representaba a la fracción principista. También se consultó Diario del Plata, cuyos editores en 1922 aclaraban su identificación: "desde hace diez años con el Partido Nacional, y en oposición radical con las normas políticas, económicas y sociales del batllismo" ${ }^{6}$

Asimismo, se han consultado dos libros de Herrera escritos en 1923, a escasos meses de su derrota presidencial, como muestra del significado político que tuvo en su biografía. Herrera en Una etapa, fechado en Berna en el mes de junio, aprovecha la última contienda electoral para reflexionar sobre el engranaje del acontecimiento en el marco de la evolución ascendente de la República para alcanzar su libertad política, la que a su juicio seguía siendo escamoteada y ultrajada por su tradicional rival colorado. El eje del texto está puesto en el papel histórico y presente del heroísmo del Partido Nacional en su lucha por aquella sagrada bandera. Un mes más tarde, en París, Herrera finalizaba En la Brecha, un libro en el que hilvanaba un conjunto de documentos recientes de su actuación política como presidente del directorio de su partido hasta su renuncia al puesto en medio de la campaña del 22. Los textos seleccionados hacen hincapié en sus contribuciones a cuestiones sociales y políticas, y a la vez incorpora publicaciones y discursos del año electoral.

\section{La campaña nacionalista en 1922}

En 1922, el Partido Nacional asistió a una crispada disputa interna para definir la candidatura presidencial y los nombres para la renovación del Consejo Nacional de Administración en noviembre. Dos meses antes, en las elecciones internas del partido, triunfó la candidatura de Luis Alberto de Herrera para la primera magistratura, y la de Carlos María Morales y Alfredo García Morales, como consejeros. La fórmula vencida fue la de Arturo Lussich como presidente y la de Martín C. Martínez y Leonel Aguirre para consejeros. El radicalismo blanco, que no había simpatizado con ninguna de las dos precandidaturas, tomó la decisión de acompañar a Herrera (Zubillaga: 1979, 36-37).

En la previa a los comicios partidarios, El País hizo una intensa propaganda a favor de Lussich, Martínez y Aguirre. ${ }^{7}$ Después de la derrota, los

\footnotetext{
6 "Ante la crisis de Noviembre: Buenas perspectivas", Diario del Plata (18/10/22), p. 3. El director del medio fue un dirigente polémico del nacionalismo llamado Juan Andrés Ramírez. Asimismo, se consultó el periódico Bandera Blanca, surgido en diciembre de 1922 y dirigido por "dos jóvenes bachilleres". "Bandera Blanca”, La Democracia (5/12/22), p. 1. Según Lindahl (1971), El País y Diario del Plata tenían mayor tirada que La Democracia (395-397). Para mayor información sobre la prensa nacionalista véase: Rodríguez y Ruiz (1990).

7 “Comité Nacional pro-candidaturas de Lussich y Martínez", El País (12/09/22), p. 5.
} 
candidatos reconocieron que Herrera encarnaba la fracción mayoritaria dentro del partido, y que compitieron desde una posición de desventaja y debilidad, porque este había contado con mayores recursos materiales y había comenzado su proselitismo un año antes. ${ }^{8}$ Sus apreciaciones no dejan de ser ciertas, puesto que Herrera, como presidente del directorio, había introducido renovaciones en la forma de hacer política, lo que implicaba mantener asiduos y significativos contactos personales con sus bases a partir de viajes a los departamentos del interior del país, asambleas políticas, visitas a clubes partidarios, asados y participación en homenajes (Haedo, 1990b: 20-27, Manini Ríos, 1972: 207-211). En El País se hacían algunas críticas indirectas al "caudillaje" de Herrera en el seno partido, lo que era visto como un riesgo para el futuro de la colectividad blanca. Así alertaron que los "caudillos" podían ser fuerzas orientadas para el bien, o sea, "conductores de almas" como era el caso de Aparicio Saravia y del argentino Hipólito Yrigoyen, o perturbadoras, sin ejemplificar. ${ }^{9}$ En una editorial en la que se recordaban los cuatro años de existencia de El País se destacaba que sus fundadores, como los hombres que guiaban la empresa en ese tiempo, profesaban "culto a los principios" del "dogma republicano" en "periodos [en] que todo parece quebrarse por el avance del personalismo". ${ }^{10}$ Diario del Plata también simpatizó con la candidatura de Lussich por ser "un modelo acabado de las más altas virtudes, lección viviente de absoluta inhibición del yo frente a las exigencias del patriotismo". En cuanto a Herrera proclamaban que era ingobernable, y aunque reconocían sus "hermosos antecedentes cívicos" el problema residía en "su actividad inquieta no siempre bien disciplinada, su inteligencia original en perpetua rebelión con todos los cánones consagrados". ${ }^{11}$

La Democracia, que no ignoraba las críticas de los correligionarios, explicaba que en el Partido Nacional no reinaban "falsas deidades", como sucedía con su principal antagonista José Batlle y Ordóñez. ${ }^{12}$ A diferencia de los colorados, los blancos eran comprensivos con sus divisiones internas: "Ningún nacionalista ha sido atacado, lastimado, por nosotros. En todos hemos respetado y reconocido [...] el libérrimo derecho de alentar las más diversas convicciones. Ahora a estrechar filas". ${ }^{13}$ Esto, además, los diferenciaba del Partido Colorado, fraccionado por irreconciliables intereses y que castigaba a los suyos. ${ }^{14}$ En cambio, el nacionalismo era una "agrupación de hombres libres",

\footnotetext{
8 "Reminiscencia", El País (22/09/22), p. 3; “Una gran lección de civismo: las renuncias de los doctores A. Lussich y Martín C. Martínez", El País (19/09/22), p. 3.

9 "El Caudillo", El País (10/09/22), p. 3.

10 "A los cuatro años: Cómo se fundó El País", El País (14/09/22), p. 3.

11 "Ante la crisis de Noviembre: Buenas perspectivas", Diario del Plata (18/10/22), p. 3.

12 "Camino al triunfo", La Democracia (21/11/22), p. 3.

13 "El pueblo habló...", La Democracia (12/09/22), p. 1. También véase: "La cultura nacionalista", La Democracia (14/09/22), p. 1.

14 "Otra vez... ¿Ruptura definitiva?", El País (15/11/22), p. 3; "El batllismo frente al país", La Democracia (5/11/22), p. 1.
} 
con capacidad de opinar, batallar por una idea o aspiración. ${ }^{15}$ Las elecciones internas de setiembre fueron visualizadas, desde La Democracia, como una “jornada ejemplarizadora"16 de disciplina partidaria, a partir de la cual el partido debía sostener la unidad, la cordura y la armonía, sin traidores ni rencores. ${ }^{17}$ No obstante, los artículos muestran una realidad de dificultades: en una de las notas se criticaba a los "derrotistas" o "pesimistas" como los "verdaderos enemigos", es decir, aquellos "malos partidarios" que sembraban "desánimo" azuzando "fantasmas":

“¿Para qué vamos a triunfar? - ¿Ha pensado, usted, en lo que puede suceder? - ¿No advierte los graves inconvenientes del gobierno? - ¿No ve que el país está en ruinas? - ¿Y si el régimen no entrega? - ¿Y si entrega y se nos complica la vida?"18

Lussich, en su carta de renuncia a la presidencia, aludió a los valores de honor y de fidelidad de la tradición nacionalista, y con el objetivo de la victoria deberían "unir voluntades". ${ }^{19}$ Sin embargo, entre sus militantes cundía el desánimo y la impotencia. La Democracia también propugnaba que el Partido Nacional era "uno solo". ${ }^{20}$ A principios de octubre, denunciaron a El País por insinuar de forma "injusta" que hubo fraude en los comicios internos y una vez más reivindicaron la pureza del acto electoral, con una frase final muy sugestiva: "los nacionalistas piensan de muy distinto modo". ${ }^{21}$ Es decir, aquellos que sembraban la desunión y difamaban no pensaban ni actuaban como nacionalistas. Estos detalles en su conjunto demuestran las divisiones existentes, que con el correr de la década se irían profundizando.

Desde la óptica herrerista, era imprescindible para cooptar al ciudadano desinteresado, imparcial o indiferente de la política, mostrarle que la práctica interna del partido era democrática. Se quejaban de que algunos se alejaban del "recto camino" haciendo campaña con el "encanto de hombres brillantes", pero no señala quiénes eran esos individuos. Con vigor exigían el reconocimiento de Herrera: "porque si no se hace los fervientes seguidores del partido estarían desorientados y los votantes imparciales desconfiarían del partido". ${ }^{22}$ La crítica

\footnotetext{
15 "El derecho al gobierno del país", La Democracia (21/11/22), p. 1. La insistencia en la idea del "imperio de la libertad" dentro del partido es un concepto fundamental porque era una garantía que eso sería norma del futuro gobierno nacionalista: "La ley del partido", La Democracia (1/10/22), p. 1.

16 "La acción futura", La Democracia (13/09/22), p. 1.

17 "Pueblo libre", La Democracia (13/09/22), p. 1. En la misma línea, se pronunció el herrerismo:

"El Congreso Nacional", La Democracia (11/10/22), p. 1; Por la unión del Partido, La Democracia (15/10/22), p. 1.

18 "El derrotista", La Democracia (15/09/22), p. 1.

19 "Renuncia del Dr. Lussich", El País (19/09/22), p. 3.

20 "El gran deber", La Democracia (16/09/22), p. 1.

21 "Enormes injusticias", La Democracia (1/10/22), p. 1.

22 "El camino derecho", La Democracia (3/10/22), p. 1.
} 
tiene fundamentos, puesto que El País no hizo propaganda a favor de Herrera, limitándose a guardar silencio sobre su figura, ya que su eje siempre estaba puesto en el partido o en hombres vinculados a su sector político que se presentaban como candidatos para el parlamento.

En octubre los delegados del Congreso Elector Nacional proclamaron por unanimidad la candidatura presidencial de Herrera y de sus consejeros, como "símbolo de unión, bandera de fraternidad y de concordia". ${ }^{23}$ Sin embargo, las notas en los días previos y posteriores revelan que continuaban existiendo disidencias. Si bien La Democracia reconocía que estas eran legítimas, precisaba que más allá de ellas debía regir la "unión sagrada de los nacionalistas". ${ }^{24}$ Estos llamados a la unidad partidaria demuestran que las discrepancias y tensiones no habían sido selladas. El País calmaba a sus simpatizantes recordándoles que las renuncias de sus candidatos habían sido un acto de "disciplina partidaria" porque la "causa nacionalista está por arriba de las tendencias". ${ }^{25}$ De hecho, Lussich había subrayado que el Partido Nacional era "la más poderosa fuerza de control que cuenta el país". ${ }^{26}$ En este punto se reconocía el papel desempeñado por el partido como minoría en el CNA cuya influencia había implicado una importante función de "fiscalización". ${ }^{27}$ Sin embargo, aparecieron varias notas que criticaban la pérdida de atribuciones del poder ejecutivo. ${ }^{28}$

Igualmente, en la perspectiva nacionalista, el partido era una "necesidad de la república" frente al exclusivismo y sectarismo de los colorados. ${ }^{29}$ Estas ideas se condensan en la siguiente frase: "El Uruguay es una excepción entre todas las naciones civilizadas; es el único país en que un partido político permanezca, sin interrupción, más de cincuenta años al frente de sus destinos". ${ }^{30}$ Se recurre al recuerdo de los infortunios, de las injusticias y de las adversidades como argumento de legitimación de su derecho a la victoria. Este historial de sufrimiento no solo era negativo, sino que a la vez se unía a las virtudes de sacrificio o abnegación, honor, responsabilidad, firmeza, civismo desinteresado y tolerancia de sus dirigentes pasados y presentes. La masa militante también participaba de las virtudes de sus políticos, y se componía de

\footnotetext{
23 "Manifiesto del Congreso Elector Nacional", La Democracia (20/10/22), p. 1; "La fórmula de la fraternidad nacionalista", La Democracia (17/10/22), p. 1; "La fórmula proclamada", La Democracia (17/10/22), p. 1; “Acuerdo nacionalista”, Diario del Plata (15/10/22), p. 3.

24 "Manifiesto del Congreso Elector Nacional", La Democracia (20/10/22), p. 1.

25 "Precisando, el porqué de las renuncias", El País (21/09/22), p. 3. En la misma línea se expresaba el herrerismo: "Disciplinado y entusiasta", La Democracia (4/10/22), p. 1.

26 "Renuncia del Dr. Lussich", El País (19/09/22), p. 3.

27 "Disyuntiva", La Democracia (2/11/22), p. 1.

28 "Experiencia institucional: la desintegración del ejecutivo", El País (12/09/22), p. 3; "Lo mejor, enemigo de lo bueno, El País (13/09/22), p. 3.

29 "Hacemos falta", El País (17/11/22), p. 3.

30 "El ascenso al poder: Una cuestión nacional”, El País (21/09/22), p. 3.
} 
"población laboriosa", de "cuadros pacíficos", "ciudadanos auténticos" y se renovaba con una entusiasta y optimista juventud. ${ }^{31}$

La retórica nacionalista insistía en el hecho de ser un partido democrático, republicano, defensor de las libertades y derechos. Esta prédica reflejada en el funcionamiento interno del partido era garantía para la ciudadanía. ${ }^{32}$ El triunfo del Partido Nacional permitiría nutrir a la nación de "muy loables" virtudes: orden, cultura, trabajo, justicia, fraternidad, tolerancia, dignidad, concordia, honradez, espíritu patriótico, moralidad política y administrativa, las cuales formaban parte de lo que llamaban "nuestro credo". ${ }^{33}$

En esta dinámica, el nacionalismo se presentaba como la "gran causa popular". Este último aspecto es significativo, ya que se apelaba al pueblo en su conjunto y de forma integradora. Se pedía confianza en la capacidad del Partido Nacional para la obra de "renovación", "engrandecimiento" y "resurgimiento nacional" -moral y material- de la República. Su anhelo era que la "Patria sea para todos", para las "fuerzas vivas del país", desde obreros, trabajadores rurales, maestras, profesionales, empleados públicos hasta empresarios $\mathrm{y}$ hacendados. ${ }^{34}$ Así pues, se intentaba convocar a todos los miembros de la sociedad, invitándolos a formar parte de su colectividad. Además, prometía esperanza y salvación depositada en una "nueva era" y en la realización de una "verdadera democracia". Se presentaba al oficialismo como la antítesis del Partido Nacional, y no dejaba de ser nombrado como "enemigo": abusaba de su poder, era opresor y sembraba odios, era un "gobierno de ladrones" 35 y que "sólo agita el membrete de la acción republicana, desmentida en cada instante". 36

La prensa partidaria trasmitió que la victoria sería arrolladora y que era posible observar la agonía, la bancarrota y el desprestigio del "régimen" y su "visible impopularidad". ${ }^{37}$ El diagnóstico del presente era lapidario. En cuanto a la esfera política todavía no se habían extirpado los hábitos y prácticas de impureza democrática, y en lo económico los males eran graves en lo que

\footnotetext{
31 "El gran deber", La Democracia (16/09/22), p. 1; "Por respeto a sí mismo y al país", La Democracia (5/12/22), p. 1. Si bien sostenían que el partido se componía por cuadros heterogéneos es interesante como en algunas ocasiones se reconoce que el peso electoral lo tenían en la campaña: "Montevideo y la campaña", La Democracia (4/11/22), p. 1; "Compañero", La Democracia (23/11/22), p. 2.

32 "El gran deber", La Democracia (16/09/22), p. 1.

33 "Las candidaturas populares Lussich, Martínez, Aguirre", El País (12/09/22), p. 5; "La acción futura", La Democracia (13/09/22), p. 1; "Prédica y práctica”, La Democracia (13/09/22), p. 1.

34 "A formar", El País (23/11/22), p. 3; "El comité de Acción Cívica al País", La Democracia (12/11/22), p. 3; “Los obreros, los maestros, los menesterosos”, El País (22/11/22), p. 3.

35 "El Partido Nacional, luchará...", El País (11/11/22), p. 3.

36 "El pueblo habló...", La Democracia (12/09/22), p. 1.

37 "El ascenso al poder: Una cuestión nacional", El País (21/09/22), p. 3; "Contra un régimen", La Democracia (4/10/22), p. 1; “Vísperas del triunfo”, La Democracia (25/11/22), p. 1.
} 
refería a la disminución de la iniciativa privada, al aumento del gasto público, a las enormes deudas contraídas por el Estado y a los altos impuestos al consumo. Asimismo, se denunciaba un contexto de crisis agrícola y ganadera. ${ }^{38}$ El acceso al poder permitiría iniciar una etapa de reconstrucción y de finalización de la "aventura socializante del batllismo", una "obra disolvente y perniciosa", "dictadura legalizada de un partido en descomposición", régimen despótico, porfirista, intolerante, oligárquico, exclusivista, sectario $\mathrm{y}$ demagógico. ${ }^{39}$ Por ello, reivindicaban la necesidad de la rotación de las agrupaciones políticas como "el más alto ideal a que pueda aspirar un pueblo democrático". ${ }^{40}$ En esta línea, trasmitían a los ciudadanos tranquilidad y confianza y explicaban que gracias a la desmembración del poder ejecutivo el gobierno de un partido no implicaría la "proscripción ni anulación del otro", además el Partido Colorado seguiría siendo la mayoría del CNA y en el senado. Para Diario del Plata, la gestión de este organismo "es mucho más importante que la rama unipersonal del Ejecutivo". ${ }^{41}$

Según la prensa blanca, el batllismo infundía el temor de que si el nacionalismo ganaba se iniciaría una etapa de desgobierno en la república. ${ }^{42} \mathrm{El}$ Partido Nacional se defendía prometiendo una buena administración y un accionar de tolerancia de las libertades, sin limitarse al ámbito político, ya que el partido había realizado extensas contribuciones en cuestiones económicas y sociales. ${ }^{43}$ Así se desvinculaban de las acusaciones de ser un partido conservador de los "privilegiados de la fortuna", anacrónico y asociado a los hacendados. ${ }^{44}$ Esto fue rebatido por los nacionalistas: por un lado aclaraban que en su tradición partidaria el pasado se había construido desde los campos de batalla, pero por otro lado siempre respetaron la legalidad y los comicios libres, tomando la "victoria cívica" de julio de 1916 como un caso paradigmático. En

\footnotetext{
38 "La lucha de noviembre", La Democracia (19/10/22), p. 1; "La bancarrota del país", La Democracia (24/10/22), p. 1; “Contra un régimen", La Democracia (2/11/22), p. 1; "En el Uruguay, la mesa del proletario es la mesa más sucia y más cara del mundo", La Democracia (11/11/22), p. 1; “La aventura socializante del batllismo", La Democracia (19/11/22), p. 1.

39 "El Partido Nacional: luchará...", El País (11/11/22), p. 3; "Hasta agotar el tema: Las grandes iniciativas batllistas", El País (12/11/22), p. 3; "El sapo y la luciérnaga", La Democracia (4/11/22), p. 1; "La aventura socializante, La Democracia (19/11/22), p. 1; "El batllismo contra el país", La Democracia (23/11/22), p. 2; "Vísperas del triunfo", La Democracia (25/11/22), p. 1; "A votar", Diario del Plata (26/11/22), p. 3.

40 "Contra el porfirismo", La Democracia (7/11/22), p. 1.

41 "El problema de noviembre", Diario del Plata (15/10/22), p. 3; "Actualidad", Diario del Plata (24/10/22), p. 3.

42 "Proclamas curiosas", El País (7/11/22), p. 5.

43 "Acción fecunda", La Democracia (4/10/22), p. 1; "El conceptuoso discurso del Dr. Carlos María Morales", La Democracia (21/10/22), p. 1; "Los obreros, los maestros, los menesterosos", El País (22/11/22), p. 3. En este último artículo se reconocía el aporte de Lorenzo Carnelli a las leyes de jubilaciones.

44 "La aventura socializante”, La Democracia (19/11/22), p. 1; “Partido de los hacendados", El País (16/11/22), p. 3.
} 
tal sentido, el nacionalismo, en el que Herrera colaboró con su enfoque historicista, nutrió su discurso con múltiples personajes e hitos del pasado. Al mismo tiempo, construyó una identidad del Partido a lo largo del tiempo reforzando la identificación de la historia partidaria con la del propio Uruguay en su avance civilizatorio.

Ese pasado se amalgamaba con un presente en el que el nacionalismo cobijaba a las "fuerzas vivas del país" en un programa de "vibrante actualidad", que sellaría un porvenir de "resurgimiento" y "progreso", donde la libertad y la justicia de un gobierno republicano serían una realidad. ${ }^{45}$ Sin embargo, sí se reconocía que las clases conservadoras serían más respetadas por un gobierno nacionalista que en uno batllista, caracterizado por su odio al capital y su intolerancia religiosa. ${ }^{46}$

\section{El nacionalismo: una religión cívica}

Los nacionalistas tenían su "credo": entre sus devociones estaba el "culto a la democracia" 47 y la creencia de ser portadores de una "vocación democrática superior" 48 o de ser los "verdaderos intérpretes de la voluntad de la nación". ${ }^{49}$ Cuando el duplo Herrera-Morales triunfó en la interna partidaria, este se transformó en "fórmula consagrada: la que el pueblo soberano ungió, la que alumbró su entraña milagrosa: el binomio de fierro" ${ }^{50} \mathrm{Al}$ mismo tiempo demostró la "unión sagrada de los nacionalistas". ${ }^{51}$ Como se ha visto, la insistencia en el funcionamiento democrático del partido era garantía de una eficaz administración de gobierno, por ello se repetía que: "los odios y las intransigencias sectarias no caben en almas consagradas al culto de los altos ideales democráticos". ${ }^{52}$ Herrera concebía el ejercicio de gobierno como un "apostolado". ${ }^{53}$ Sus acólitos situaban al pueblo nacionalista en el centro del discurso: "Se acabaron los tiempos en que nuestras generosas multitudes eran traídas y llevadas, sin oírlas, sin tomarlas en cuenta, sin acatar su sagrada y

\footnotetext{
45 "El Partido Nacional y los problemas actuales", El País (17/11/22), p. 3; “El conceptuoso discurso del Dr. Carlos María Morales", La Democracia (21/10/22), 1; “A votar! (sic.)", La Democracia (26/11/22), p. 2.

46 "Deber ineludible: hay que votar", Diario del Plata (25/11/22), p. 3.

47 "El gran deber", La Democracia (16/09/22), p. 1.

48 "La ley del partido", La Democracia (1/10/22), p. 1.

49 "En grandiosa asamblea, fueron aclamados anoche los candidatos del Partido a los primeros puestos del país", La Democracia (21/10/22), p. 1; “Camino al triunfo", La Democracia (21/11/22), p. 3 .

50 "Un veredicto sagrado y definitivo", La Democracia (1/10/22), p. 1.

51 "Manifiesto del Congreso Elector Nacional", La Democracia (20/10/22), p. 1.

52 "En grandiosa asamblea, fueron aclamados anoche los candidatos del Partido a los primeros puestos del país", La Democracia (21/10/22), p. 1.

53 "Programa de gobierno del Dr. Luis Alberto de Herrera", La Democracia (21/10/22), p. 1.
} 
suprema voluntad". Este aspecto se iría acentuando en las siguientes campañas electorales (Cerrano, 2017; Cerrano y Saravia, 2020).

La historia del Partido Nacional era la de un "via-crusis (sic.)" de inauditos sacrificios, adversidades y dolores, ${ }^{54}$ siendo para el país "el mayor milagro de energía cívica y triunfal resistencia contra el adversario destino". ${ }^{55}$ Herrera (1998 [1923]) se postraba ante los "ancianos apostólicos, que atizan el fuego de la convicción en el alma de sus nietos" (154). Asimismo, recomendaba: "honra a tu padre y a tu madre, como reza el mandamiento; y los padres de la democracia son sus héroes y mártires" (169). En una exhortación a la votación de noviembre se rogaba: "Nacionalistas: por la sagrada memoria de nuestros mayores, por el imperioso deber que la patria nos reclama, a votar y a triunfar! (sic.)". ${ }^{56}$

Para Herrera, la masa era portadora de virtudes: el sufrimiento, el trabajo, la sabiduría y el patriotismo, los "sanos propósitos" y el "consejo providencial". ${ }^{57}$ En sintonía con esta convicción de fe en el pueblo, unos días antes de la elección había vaticinado que "únicamente un acontecimiento sobrenatural y fuera de toda lógica, puede impedir la victoria del pueblo, que se levanta como una fuerza poderosa de la naturaleza para romper las cadenas forjadas por el batllismo". ${ }^{58}$

Finalmente, Herrera no alcanzó la presidencia. Desde Europa, escribió que las urnas habían expresado "la voz de la República" y que "también esta vez la honda de David derribó al gigante" (Herrera, 1998 [1923]), p. 131). Asimismo, en un lenguaje profundamente cristiano sostuvo la colaboración del Partido Nacional en el "descendimiento de la cruz" (161) después del martirio. "La prosperidad nacionalista de hoy se asienta sobre el martirologio nacionalista de ayer" (167-168). Sin embargo, consideraba que no era solo atribuible a su partido "el patrimonio de la virtud democrática" o el culto a los "ideales superiores", por ello "rinde amplio aplauso a los ciudadanos de otras filiaciones que comparten las rudas pruebas de la oposición" (161). No obstante, al final, el fraude consumó la "herejía", la "mentira", la "delincuencia", la "corrupción", el "atentado" sobre los "espíritus honrados" o el "pueblo heroico" (183-200).

\footnotetext{
54 "A votar! (sic.)", La Democracia (18/10/22), p. 1.

55 "Un milagro de energía cívica", El País (16/11/22), p. 3.

56 "A votar y a triunfar! (sic.)", La Democracia (26/11/22), p. 1; "11 de octubre de 1891", La Democracia (11/10/22), p. 2.

57 "Categóricas declaraciones políticas del Dr. Luis Alberto de Herrera", La Democracia (11/10/22), p. 1.

58 "Contra el batllismo", La Democracia (24/11/22), p. 2.
} 


\section{El lenguaje de la guerra y de la medicina}

Los comicios de noviembre eran para el partido una "batalla", una "cruzada nacional" de un "formidable ejército ciudadano" no violento, en la que la unidad sin "ninguna deserción" era un elemento central para la victoria frente al enemigo. ${ }^{59}$ Las guerras perdidas por la división de sus generales eran aleccionadoras de la "necesidad de callar las divergencias". ${ }^{60}$ En esta dinámica binaria, el Partido Nacional representaba una "enorme fuerza cívica, poderosamente organizada, pacífica y entusiasta, tolerante" cuya misión era "la defensa de los intereses comunes" ${ }^{61}$ En una valoración encomiástica de $\mathrm{La}$ Democracia, Herrera, un "nombre ilustre", había conquistado el "cariño" de la muchedumbre "con la rectitud batalladora de su vida, templada al rigor de la lucha" y había sido "consagrado" como "guía" de la "cruzada cívica". ${ }^{62}$

El Partido Nacional llevaba tras de sí a la "opinión sana hacia una nueva era de libertad política", ${ }^{63}$ o en la misma línea, lo acompañaban las "fuerzas independientes y sanas del país". ${ }^{64}$ De tal modo, la "orientación patriótica" y la "organización del partido" eran sanas, así como sus ideas, sus propósitos y sus principios. Si ellos estaban del lado de los sanos, en el polo opuesto se ubicaban sus adversarios políticos, por más que sean escasas las referencias a "malsanos", y no se utilice la palabra enfermo. También los colorados tenían "olor a muerto" o que en su agonía "no quieren morir". ${ }^{65}$ En esta concepción, se realizaba una completa descategorización del adversario, puesto que al carecer de vida su tiempo político ya estaría acabado y no tendrían ninguna capacidad de ganar la elección ni de gobernar. A pesar de esto, es importante remarcar que Herrera prometió reunir entre sus colaboradores a hombres de "diversas filas", es decir, no solo a los sanos, sino además a los prestigiosos y honestos. ${ }^{66} \mathrm{En}$ su último discurso del año, el líder blanco acusó a sus adversarios, quienes con su sectarismo, productor de odios, habían "envenenado la vida colectiva", y denunció al fraude como un "cáncer". ${ }^{67}$ La idea de lo sano también conecta con

\footnotetext{
59 “Unidos", La Democracia (12/10/22), p. 1; “A votar", La Democracia (18/10/22), p. 1; “Una cruzada nacional", La Democracia (31/10/22), p. 1; "Haga Vd. Lo que quiera", La Democracia (31/10/22), p. 1.

60 "Por la unión, por el triunfo", El País (23/11/22), p. 3.

61 "Realidad patriótica", La Democracia (12/10/22), p. 1.

62 "El candidato del partido", La Democracia (14/10/22), p. 1; "Legalmente hemos triunfado", Bandera Blanca (1/12/22), p. 2.

63 "Mañana viernes, tendrá lugar en el Teatro Artigas la proclamación pública de la fórmula de la fraternidad nacionalista", La Democracia (19/10/22), p. 1.

64 "El batllismo contra el país", La Democracia (23/11/22), p. 2.

65 "Por la concordia nacional", La Democracia (16/11/22), p. 1; “La sucia maniobra", La Democracia (17/11/22), p. 1; “Huele a muerto", La Democracia (2/12/22), p. 1.

66 "Programa de gobierno del Dr. Luis Alberto de Herrera", La Democracia (21/10/22), p. 1.

67 "Haciendo democracia: del Dr. Luis Alberto de Herrera, a sus electores", La Democracia (10/12/22), p. 1.
} 
la pureza como una virtud en la que un "buen nacionalista" es ejemplo, en esta tónica los colorados son denostados de "impuros".

Por otra parte, es incesante la referencia a la entrega heroica de la sangre generosa, ardiente y fecunda de los nacionalistas que sirvieron a los intereses del país. La superioridad de los blancos frente a los demás se sintetiza de forma muy simbólica en la siguiente frase: "el Partido Nacional ha sido también el único en derramar su sangre por la libertad del sufragio". ${ }^{68} \mathrm{Si}$ bien hay un constante recuerdo a la época de las reivindicaciones armadas, es importante puntualizar la significativa cantidad de artículos que insisten en la obligación de ejercer el derecho al voto - no abstenerse- en un contexto en el que ya se habían clausurado las "elecciones sombreadas por la coacción". ${ }^{69}$ En esta lógica, votar era un deber de un "buen patriota" -lo que incluía a todos los ciudadanos habilitados- y de un "buen nacionalista", no hacerlo era traición. ${ }^{70}$

\section{Herrera en la campaña electoral}

El 20 de octubre en el teatro Artigas, colmado de cuatrocientos correligionarios, Herrera presentó su programa de gobierno. El escenario fue adornado con "banderas y luces" y se contrató una "banda de música" para la celebración de un acto que se inició con el canto del himno nacional. Las notas fotográficas muestran que en los palcos estuvieron las "damas nacionalistas" junto a sus familias, las que "ponían una nota de inefable belleza y exquisita distinción" y quienes arrojaron a su candidato presidencial "grandes ramos de flores" ${ }^{71}$

Herrera destacó que con su "mano en el corazón" hablaba a "los hombres de [su] fe política, y sobre todo a la nación, que está por encima de partidos", bajo la promesa de que sería el "presidente de todos los orientales". En el "orden económico" se comprometió a reducir los gastos del Estado, ${ }^{72}$ en cuanto a las contrataciones de empleados públicos no se crearían nuevos

\footnotetext{
68 "La realidad de los hechos", La Democracia (3/12/22), p. 1; “El derecho al gobierno del país", La Democracia (21/11/22), p. 1; "El triunfo", El País (25/11/22), p. 3.

69 "Buen aliado", La Democracia (3/10/22), p. 1; “La balota”, La Democracia (14/10/22), p. 1.

70 "El comité de Acción Cívica al País", La Democracia (12/11/22), p. 3; "Quince días", El País (11/11/22), p. 3; "Consigna cívica: todos deben votar", Diario del Plata (27/10/22), p. 3. En un recuadro, El País (23/11/22) colocó la siguiente frase: “Quien se abstiene de votar es indigno de llamarse nacional".

71 "Esta noche, ante miles de ciudadanos, tendrá lugar en el Teatro Artigas la proclamación pública de los candidatos del partido", La Democracia (20/10/22), p. 1; "En grandiosa asamblea, fueron aclamados anoche los candidatos del Partido a los primeros puestos del país", La Democracia (21/10/22), p. 1; “Gran acto cívico nacionalista", Diario del Plata (21/10/22), p. 3. Una vez finalizado el acto una "gran manifestación" se dirigió desde el teatro al Club Nacional, allí se entonó el himno y se aclamó a Herrera quien dijo unas breves palabras.

${ }^{72}$ Esta idea se trasmitía en la prensa partidaria nacionalista de manera constante.
} 
puestos y las vacantes, "de ser posible", se suprimirían. ${ }^{73}$ Partía de considerar que los impuestos eran "insaciables" y una dificultad para estimular la producción. En el "orden filosófico" recordó que en Uruguay la Iglesia se separó del Estado y esto había sido positivo, así destacó que el Partido Nacional salvaguardaría la libertad de conciencia. Asimismo, se refirió a la constitución, la que "reduce, en mucho, el radio de la acción presidencial", considerando que "alguna vez ha de renovarse el ciclo de las grandes presidencias" y enfatizó que "ningún título vale más que el del primer magistrado". ${ }^{74}$ Remarcó su creencia en las "virtudes de la coparticipación" y de los avances de la constitución de 1917, aunque resaltó que todavía no se había arribado a una "democracia auténtica". Con relación al ejército y a la policía insistió en que se mantuvieran al margen de las contiendas políticas. Un apartado importante mereció la problemática social, en su convicción de que los conflictos entre capitalistas y obreros deberían encauzarse en el respeto de los derechos tanto de huelga como de trabajo, manteniéndose el orden público. Y en cuanto a las reformas sociales se declaró partidario de las "juiciosas" y de las que forman parte del "espíritu avanzado de la época" como la ley de las ocho horas y la de las jubilaciones. La primera garantizaba que "la alegría del vivir no es privilegio de clase" y la segunda faltaba ampliarse a más ciudadanos para alcanzar una "holgada vejez" como "justo premio a la labor tenaz". ${ }^{75}$ También sostuvo que era perentorio avanzar en la "organización legal de los sindicatos". En su disertación se mostró sensible a las injusticias que pesan sobre los humildes, las mujeres y los niños, prometiendo su "positiva protección". No se olvidó de dar un mensaje a los jóvenes, quienes serían motivados a fortalecerse en el trabajo y en la práctica de la gimnasia. De hecho, reivindicó su "entusiasmo ilimitado por los juegos atléticos". Además, el programa dedica espacio a la importancia de la educación de jóvenes y niños "para librarla de la malsana influencia oficial". A su vez, propuso mejorar la "atención social" de las "casas hospitalarias" lo mismo que de los establecimientos carcelarios. En cuanto a la política exterior se comprometió a su "cuidadosa atención" a fin de potenciar la "misión continental" americana unida por una tradición común. En su conclusión expresó:

\footnotetext{
${ }^{73}$ El tema del exceso de empleados públicos fue una crítica constante del nacionalismo al partido de gobierno, al mismo tiempo aclaraban que en caso de triunfar el Partido Nacional respetaría los "derechos adquiridos, amparando al empleado digno y competente, sin subordinar los ascensos a un criterio puramente político". "El conceptuoso discurso del Dr. Carlos María Morales", La Democracia (21/10/22), p. 1; "Compañero”, La Democracia (23/11/22), p. 2.

74 "Programa de gobierno del Dr. Luis Alberto de Herrera", La Democracia (21/10/22), p. 1. Hacia el final de la lectura remarcó nuevamente que: "que el sistema vigente restringe, de manera notoria, el poder presidencial".

${ }^{75}$ En lo social el programa mantenía continuidad con las líneas trazadas por el programa del partido en 1906 y con el de 1915: Barrán y Nahum (1981: 408-414); Herrera, (1991: 299-317) y Lindahl (1971: 402-403).
} 
"acabo de hablar como siento, como soy, como siempre he pensado [...] he tratado de recoger la palpitación de las multitudes libres en cuyo seno me crié [sic.] y aprendí a amar el verbo de la democracia y de cuyo seno salgo, empujado por la indulgencia del pueblo, a cumplir, señores, mi destino: a cosechar rosas y espinas, a darme, por entero, a la causa de $\mathrm{mi}$ país!" ${ }^{76}$

Unos días antes de este acontecimiento, en una entrevista, Herrera había adelantado algunos principios medulares de su cosmovisión política: "sobre mi partido, está mi patria [...] y que el Estado no es asilo benéfico de tal o cual partido". No faltó su reivindicación a la "sana coparticipación de ciudadanos aptos y probos" y garantizó que sería el "presidente de todos los orientales". ${ }^{77}$ Asimismo, como en el Teatro Artigas, prometió la reducción del gasto público "sin crear nuevos impuestos". ${ }^{78}$ De la entrevista es interesante su respuesta a la pregunta del periodista de que el nacionalismo "es sinónimo de conservatismo", y que a él se lo había acusado de "retrógrado" y "enemigo de las modernas tendencias sociológicas". En primer lugar, refirió "me importa que no se perpetúe el error con que el oficialismo considera que las reformas sociales son patrimonio suyo", y le reprochó la utilización de los obreros "como halago electorero". Recordó que él junto a otros correligionarios había colaborado en proyectos de reforma social anteriores al "ciclo reformista del oficialismo". Como en el programa, se manifestó de acuerdo con el derecho de huelga y la legítima jornada de ocho horas, el problema era cómo hacer "provechosas o soportables" las dieciséis restantes, pero aclaró que esta simpatía por la "moderna legislación social" no debía acompañarse de un "espíritu de sistemática agresión contra el capital". E insistió en la idea de que el poder público "está obligado a la protección y defensa de todos los elementos sociales", favoreciendo "especialmente a los más desamparados" sin estimular "funestas rebeldías" y "animosidades". ${ }^{79}$ Desde el Diario del Plata se consideró que el programa coincidía con las "aspiraciones de todo el país. Exento de peligrosos radicalismos, libre de agresividades injustificadas, colocado en un

\footnotetext{
76 "Programa de gobierno del Dr. Luis Alberto de Herrera", La Democracia (21/10/22), p. 1. Una versión impresa del programa véase en: Herrera (1990 [1923]: 342-351).

${ }_{77}$ El 12 de octubre de 1922 asumió la presidencia en Argentina Marcelo T. de Alvear, desde el herrerismo se felicitó su declaración de que "gobernaría por encima de su partido", lo que lo situaba en sintonía con la posición ideológica de los blancos uruguayos: "Ejemplo democrático", La Democracia (14/10/22), p. 1.

${ }^{78}$ Desde El País se denunciaba que si ganaban los colorados se crearían nuevos impuestos y se aumentarían otros. "La amenaza que se cierne sobre el país", El País (11/11/22), p. 3.

79 "Categóricas declaraciones políticas del Dr. Luis Alberto de Herrera", La Democracia (11/10/22), p. 1.
} 
juicioso justo medio entre un avancismo insensato y un quietismo depresivo para todas las actividades fecundas" .80

Unas semanas antes de los comicios se organizó "la gran colecta nacionalista" mediante la compra de "bonos de la victoria" para nutrir al tesoro partidario. Los colaboradores quedarían registrados por "cumplir con su deber". Así pues, los miembros del partido no solo participaban de sus ideales, sino que eran persuadidos a contribuir al objetivo final con una parte de sus ingresos. Se señalaba que la organización electoral estaba inspirada en el "modelo" estadounidense. ${ }^{81}$ Una novedad de la campaña nacionalista fue el "tren relámpago" que con los candidatos y otras personalidades del partido visitó "todos los departamentos, todas sus capitales, todos los pueblos acordonados a los rieles". ${ }^{82}$ Esto posibilitaba a los simpatizantes establecer contacto directo con los candidatos, en especial con Herrera "que disfrutaba de las funciones públicas, dando la mano a la gente y dando discursos" (Vanger, 2012: 13). Según la prensa nacionalista: "el electorado no se contenta ya, con escuchar a los candidatos a través del telégrafo y del diario; quiere conocerlos personalmente, teniéndolos a su alcance". ${ }^{83}$

\section{La derrota nacionalista}

Después de los comicios del 26 de noviembre, la prensa nacionalista celebró la "victoria definitiva" frente al batllismo, "callado" y "desalentado" ante la "desastrosa derrota", aunque se reconocía que todavía faltaba cerrar el escrutinio de votos. $^{84}$ El día 28 ya aparecían noticias de fraude, pero se comentaba sobre las caras de velorio y de silencio que reinaban en las filas oficialistas. ${ }^{85}$ El 29 los ánimos estaban tensos, mientras el Partido Nacional proclamaba su triunfo, un nutrido grupo de colorados se congregó en la mansión del presidente Baltasar Brum, quien les aseguró el éxito electoral. "La jauría”, "el malón" o "el gaterío", evidencia de un lenguaje animalizando a la oposición, después se dirigió al Club Nacional y hubo un enfrentamiento

\footnotetext{
80 "Actualidad: comentarios y acotaciones", Diario del Plata (22/10/22), p. 3.

81 "La gran colecta nacionalista", La Democracia (18/10/22), p. 1; "Partido Nacional", Diario del Plata (14/11/22), p. 5; "Actividades electorales: pro-colecta nacionalista", La Democracia (18/11/22), p. 4.

82 "La gira relámpago", La Democracia (12/11/22), p. 1; "El tren relámpago", La Democracia (14/11/22), p. 1.

83 "Del ambiente", Diario del Plata (15/11/22), p. 3.

84 "El triunfo nacionalista está asegurado: Honrosa revancha y El magnífico esfuerzo", La Democracia 28/11/22), p. 1.

85 "El fraude", La Democracia (28/11/22), p. 1; "El gaterío (sic.) oficialista", La Democracia, 28/11/22, p. 1; “El desánimo", El País (28/11/22), p. 3. Solo Diario del Plata consideró que era dudosa la seguridad del triunfo que trasmitían los círculos nacionalistas: "Impresiones del momento", Diario del Plata (28/11/22), p. 3; "Prosiguiendo el comentario", Diario del Plata (30/11/22), p. 3.
} 
violento dejando varios heridos. ${ }^{86}$ Desde el 30, si bien continuaba la prédica optimista, ya se alertaba de un escrutinio defectuoso y de que habían votado los guardias civiles, quienes no estaban habilitados a hacerlo. ${ }^{87}$ Además del fraude criticaban que en las fronteras no habían permitido el ingreso al país de los ciudadanos nacionalistas que deseaban votar. ${ }^{88} \mathrm{El} 5$ de diciembre se aceptó que no alcanzaron la presidencia, pero sí la "mayoría del país". Cinco nacionalistas entraron en el senado y cincuenta y nueve en la cámara de diputados, y que de los diecinueve departamentos diez eran administraciones nacionalistas. ${ }^{89}$

El 10 de diciembre Herrera publicó "Un manifiesto al país" en el que expresó su "deuda de gratitud" con los "nobles ciudadanos" que lo honraron con su voto. Se apenó de no poder estrechar sus "manos sinceras" e hizo profesión de fe a la causa democrática y mostró comprensión con las protestas de fraude agregando las suyas en abundantes líneas, cargando con especial responsabilidad al presidente Brum. ${ }^{90}$ Tuvo ocasión de emular el ejemplo del Partido Radical argentino y de su líder Hipólito Yrigoyen, quien abandonó las agitaciones armadas por la acción pacífica, y aclaró que Uruguay todavía no poseía, como en la vecina orilla, las libertades políticas. ${ }^{91}$ Afirmó que se alejaría un tiempo del país, puesto que había sufrido en la campaña electoral, y anheló el "éxito patriótico" del nuevo gobierno. ${ }^{92}$ Unos meses más tarde Herrera (1998 [1923]) en su libro Una Etapa haría una meticulosa crítica al fraude oficialista y un profundo reconocimientos a sus votantes, con especial cariño a la fidelidad de la campaña.

\footnotetext{
86 "El Partido Nacional ha ganado las elecciones", La Democracia (29/11/22), p. 1; "El suceso sangriento: Una manifestación oficialista provoca el choque", El País (29/11/22), p. 3, "Habla 'el pibe Brum'”, El País (29/11/22), p. 3; “El malón en auge”, El País (30/11/22), p. 3; “Un colmo”, El País (30/11/22), p. 3; "Del Directorio del Partido a los correligionarios y al país", La Democracia (1/12/22), p. 1; "La realidad de los hechos", La Democracia (3/12/22), p. 1; “Los vándalos en acción", Bandera Blanca (1/12/22), p. 4.

87 "La derrota del batllismo", La Democracia (30/11/22), p. 1; "En liquidación", La Democracia (1/12/22), p. 1; “Don José Batlle está sin aceptación. Ya no lo quiere nadie", La Democracia (3/12/22), p. 2; "El triunfo", El País (30/11/22), p. 3.

88 "Juan José de Arteaga, No es cierto que nos hayan ganado", La Democracia (3/12/22), p. 1; "Los gatos peliculeros", La Democracia (3/12/22), p. 2.

89 "La jornada comicial del 26", La Democracia (5/12/22), p. 2; "Las ejemplares administraciones", La Democracia (31/12/22), p. 1.

${ }^{90}$ Unos días más tarde, el 13 de diciembre, Herrera y Brum se batieron a duelo: Haedo (1990a: 84-85).

${ }^{91}$ Herrera (1998 [1923]) en Una Etapa se explayó sobre la Argentina y su modelo democrático (202-205).

92 "Haciendo democracia: Del Dr. Luis Alberto de Herrera a sus electores", La Democracia (10/12/22), p. 1. Una versión impresa del "Manifiesto al país, después del comicio" puede verse en: Herrera (1990 [1923]: 352-356).
} 


\section{Reflexiones finales}

En este artículo se ha hecho un abordaje temporalmente delimitado de la biografía política del líder nacionalista Luis Alberto de Herrera: su primera derrota a la primera magistratura en 1922, teniendo en consideración el lenguaje político manejado por los dirigentes y medios partidarios. Una campaña en la que su liderazgo carismático y su arrastre popular estaban tibiamente expuestos en su prensa acólita, a diferencia del culto característico de los siguientes años. En 1922, la mayoría de los artículos de La Democracia, diario herrerista, estuvieron puestos en el partido y no en Herrera. Sin embargo, es posible localizar algunos aislados en los cuales su candidato y el partido se fundían en un mismo cuerpo orgánico:

"Luis Alberto de Herrera concreta hoy en sí mismo la tradición y la aspiración de la República. Es el más grande caudillo contemporáneo de multitudes libres [...] Al conjuro de su palabra y de su acción, el Partido Nacional fue un solo cerebro, un solo corazón y un solo brazo" ${ }^{93}$

En cuanto a los nacionalistas antagónicos a su personalismo no lo combatieron ni mostraron animosidad, y más bien se limitaron a guardar silencio o hacer críticas sutiles. En unos y otros primó la búsqueda de consenso, con el interés de "estrechar las filas" con el objetivo de llegar a la primera magistratura. En la retórica nacionalista, si bien existía una apelación a la unión de las voluntades individuales, respetando a cada una de ellas, se atacaba a todo aquel que pusiera en peligro la victoria con sus acciones o discursos, en un tiempo en el que la abstención y las armas habían dejado de ser una opción política.

El Partido Nacional, y el herrerismo, integraban en sus discursos diferentes dimensiones temporales: la reivindicación de un pasado que alimenta un futuro prometedor. No se manejaba una renuncia a la época de las revoluciones armadas, ya que si bien Uruguay había avanzado en el camino de la modernidad, todavía las utopías futuristas del liberalismo no eran una realidad, y por ello la lucha del pasado por la realización definitiva de la libertad política se mantenía viva por medios más pacíficos. En su viaje a Europa, posterior a la derrota, Herrera (1998 [1923]) sostuvo: “¡Arden los corazones en ensueños de libertad que los ojos nunca ven!" (131).

El lenguaje nacionalista, especialmente el de Herrera y sus propagandistas, estaba cargado de religiosidad, bajo la promesa de la esperanza y la redención de la patria -misión sagrada del Partido Nacional- las que parecían estar cada vez más cerca a pesar del "adversario destino". Tradición partidaria compuesta de héroes, mártires y apóstoles que habían entregado su

93 “Luis Alberto de Herrera”, La Democracia (1/12/22), p. 1. 
sangre en un "vía crucis" de inauditos dolores. La fe en la victoria en las elecciones del 26 de noviembre de 1922 no se quebró durante la campaña, y, de hecho, después de la derrota, se consolaban con su crecimiento de caudal electoral y de que su candidato había sido el más votado, llegando a concebir, paradojalmente, el acontecimiento como un milagro. ${ }^{94}$ La "herejía" del fraude, en palabras de Herrera, era la culpable de que la patria se privara de la reparación moral y material que el Partido Nacional podría legar al país. En indecible cantidad de artículos lamentaron y condenaron al oficialismo porque interfería para que Uruguay no pudiera estar a la par de las democracias civilizadas, como la Argentina y de otras naciones. Felizmente, desde su mirada, las virtudes de los nacionalistas (tolerancia, honor, respeto, cultura y orden), forjadas en el campo de la guerra y de la lucha cívica, eran una garantía para alcanzar una "verdadera democracia" o una "democracia superior".

Por último, el programa de gobierno leído por Herrera en el Teatro Artigas merece una reflexión. Ese día el candidato nacionalista se dirigió oportunamente a distintas audiencias y en una pieza hilvanó diferentes promesas electorales. Un punto importante fue su interés de desvincularse de la etiqueta de conservador, que pesaba sobre él y su partido, por ello buscó mostrar su sensibilidad social hacia los desamparados, compuestos por un amplio espectro: niños, mujeres, jóvenes, trabajadores y viejos. Desde su perspectiva, su actuación parlamentaria a favor de la reforma social era prueba de la veracidad de su discurso. Su interés estuvo en desenterrar la creencia instalada por el batllismo de que ellos eran los dueños del reformismo, por el contrario, para Herrera eran productores de odios y de disolución social. Esto lo diferencia de su propuesta que llevaría a evitar el conflicto entre el capital y el trabajo y solo admitiría las "reformas juiciosas". Sin embargo, tal como se desarrolló en este artículo, en la cosmovisión de Herrera y del Partido Nacional, Uruguay todavía no había conquistado definitivamente la libertad política, en tal sentido esta promesa constituyó el principal eje discursivo de su campaña electoral.

\section{Bibliografía citada}

Barrán, José Pedro y Nahum, Benjamín (1981). Batlle. Los estancieros y el imperio británico. Tomo II. Un diálogo difícil, Montevideo: Ediciones de la Banda Oriental.

Barrán, José Pedro y Nahum, Benjamín (1982). Batlle. Los estancieros y el imperio británico. Tomo III. El nacimiento del batllismo, Montevideo: Ediciones de la Banda Oriental.

Caetano, Gerardo (1993). La república conservadora (1916-1929). Tomo II: La "guerra de posiciones", Montevideo: Fin de siglo.

94 “La derrota del batllismo", La Democracia (30/11/22), p. 1. 
Caetano, Gerardo (2011). La república batllista, Montevideo: Ediciones de la Banda Oriental.

Caetano, Gerardo (2014). "Uruguay/Banda Oriental”, en Fernández Sebastián, Juan (dir.) Diccionario político y social del mundo iberoamericano. Conceptos políticos fundamentales, 1770-1870. Madrid: Universidad del país Vasco - Centro de Estudios Constitucionales, pp. 189-202.

Cerrano, Carolina (2017). "La campaña presidencial del herrerismo en 1946 desde El Debate", en Nuevo Mundo Mundos Nuevos. Disponible en: https://doi.org/10.4000/nuevomundo.70697

Cerrano, Carolina y Saravia, José (2020). “El Partido Nacional como oposición coparticipante (1920-1958)", en Garcé, Adolfo y Buchelli, Gabriel (ed.) El Partido Nacional tomo II, Montevideo.

Corbo, Daniel (2019). Cómo se construyó nuestra democracia (1897-1925): los pactos fundacionales de nuestra democracia pluralista, Montevideo: Ediciones de la Plaza.

Lindahl, Göran (1971). Batlle: Fundador de la democracia en el Uruguay, Montevideo: Arca.

Manini Ríos, Carlos (1972). Una nave en la tormenta: Una etapa de transición. 19191923, Montevideo: Imprenta Letras.

Oddone, Juan Antonio (1955). Tablas cronológicas: Poder Ejecutivo-Poder Legislativo, Montevideo: Universidad de la República, Instituto de Investigaciones Históricas.

Pérez Antón, Romeo (2018). “Las planas mayores del herrerismo: un enfoque estructural", en AA.VV Luis Alberto de Herrera: caudillo de multitudes. Vol. VIII Los Blancos, Montevideo: Ediciones de la Plaza.

Real de Azúa, Carlos (1994). Herrera: La construcción de un caudillo y de un partido, Montevideo: Cal y Canto.

Reali, Laura (2016). Herrera. La revolución del orden: Discursos y prácticas política, 1897-1929, Montevideo: Ediciones de la Banda Oriental.

Reyes Abadie, Washington (1989). Breve historia del Partido Nacional, Montevideo: Ediciones de la Banda Oriental.

Rilla, José (2008). La actualidad del pasado. Usos de la historia en la política de partidos del Uruguay (1942-1972), Montevideo: Debate.

Rodríguez Alonso, María Mercedes y Ruiz Cabrera (1990), Bibliografía de la prensa periódica de Montevideo, Montevideo: Ediciones el Galeón.

Vanger, Milton I. (2012). José Batlle y Ordóñez. La elección de 1926, Montevideo: Ediciones de la Banda Oriental.

Zubillaga, Carlos (1976). Herrera. La encrucijada nacionalista, Montevideo: Arca. 
Zubillaga, Carlos (1979). Las disidencias del tradicionalismo: El radicalismo blanco, Montevideo: Arca-CLAEH.

\section{Fuentes primarias de prensa}

La Democracia (Montevideo) (septiembre-diciembre, 1922).

El País (Montevideo) (septiembre-diciembre, 1922).

Diario del Plata (Montevideo) (septiembre-diciembre, 1922).

Bandera Blanca (Montevideo) (diciembre, 1922).

\section{Fuentes primarias de contemporáneos}

Haedo, Eduardo Víctor (1990a). Herrera. Caudillo oriental, Montevideo: Cámara de Representantes de la República Oriental del Uruguay.

Haedo, Eduardo Víctor (1990b). La caída de un régimen. Tomo II, Montevideo: Cámara de Representantes de la República Oriental del Uruguay.

Herrera, Luis Alberto (1998 [1923]), "Una etapa", en Selección de discursos y escritos periodísticos, Montevideo: Cámara de Representantes de la República Oriental del Uruguay, pp. 131-311.

Herrera, Luis Alberto (1991). Acción parlamentaria. Tomo II, Montevideo: Cámara de Representantes de la República Oriental del Uruguay.

Herrera, Luis Alberto (1990 [1923]). “En la Brecha”, en Selección de Escritos sociales. Tomo I, Montevideo: Cámara de Representantes de Uruguay, pp. 233357. 